\title{
Research on the Profit Model of Multi-Energy Interconnected Operation under New Power System Reform
}

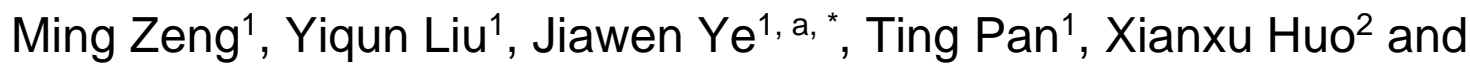 \\ Baoguo Zhao ${ }^{2}$ \\ ${ }^{1}$ State Key Laboratory for Alternate Electrical Power System with Renewable Energy Sources, North \\ China Electric Power University, Beijing, China; \\ ${ }^{2}$ State Grid Tianjin Electric Power Company, Tianjin, China.
}

*875295265@qq.com

\begin{abstract}
Keywords: Multi-energy interconnected operation; investment and construction model; service model; profit model.
\end{abstract}

\begin{abstract}
With the large-scale development and utilization of clean energy, the advancement of new electric power system reform and the im provement of the energy $\mathrm{m}$ arketization, multi-energy interconnected operation has become the main direction of energy development in the future, with the features that clean energy supplem ent, intelligent and efficient transmission and scientific terminal utilization. This paper focused on the profit $\mathrm{m}$ odel of multi-energy interconnected operation under new electric power system reform. Firstly, inve stment and construction m odel of multi-energy interconnection operation was proposed according to its construction characteristics. Secondly, the basic service models were analyzed for multi-energy interconnected operations from four aspects of electricity, thermal, information, and dem and side management. Finally, the revenue approach of each basic service was studied, based on which, the profit model of multi-energy interconnected operation was proposed, to achieve economy and sustainable profit and meet the needs of residents, enterprises and society.
\end{abstract}

\section{Introduction}

Energy is the foundation of hum an survival and development and the lifeline of the national economy. However, the sustained development of the economy and society, the continuous growth of energy production and demand, and the overexploitation and utilization of traditional fossil energy resources have caused problems such as environmental pollution, climate warming, and depletion of fossil energy. And it is a major challenge for sustainable development and energy efficiency. At the same time, globalization and the Belt and Road have further strengthened international energy cooperation, which will bring m ore diverse energy cultures, technologies, and markets. Under this background, to absorb diversified energy cultures and technologies, improve the efficiency of various energy sources, strengthen the coordination and optimization of energy system $\mathrm{s}$, and realize multi-energy complementarity are particularly important, therefore $\mathrm{m}$ ulti-energy interconnected operation systems emerged. [1,2].

The multi-energy interconnected operation is to integrate various energy resources on both supply side and dem and side into an integrated whol e. Through efficient and econom ical utilization of energy resources on the supply side, and optim ization of energy consumption on the dem and side, under the premise of maintaining energy service levels, the entire energy supply and utilization can achieve optimal economic and resource environm ental costs. As technology continues to $\mathrm{m}$ ature, integrated energy systems in the future will have broad investment prospects [3]. However, there are still many problems in current multi-energy interconnected operation, such as the immature mode of investment and construction, and the unclear profit m odel. To this end, this paper first analyzed the advantages and disadvantages of different investment construction models, then the investment and construction model of $\mathrm{m}$ ulti-energy interconnection operation was proposed according to its construction characteristics. Secondly, the basic service $\mathrm{m}$ odels were analyzed for $\mathrm{m}$ ulti-energy 
interconnected operations from four aspects of el ectricity, thermal, information, and dem and side management. Finally, the revenue approach of each basic service was studied, based on which, the profit model of $\mathrm{m}$ ulti-energy interconnected operation was proposed, to achieve econom $\mathrm{y}$ and sustainable profit and meet the needs of residents, enterprises and society.

\section{Investment and Construction Mode of Multi-Energy Interconnected Operation}

The multi-energy interconnected operation system can be invested and constructed by enterprises or users through various investm ent modes This section will explore feasible investm ent and construction modes for multi-energy interconnection operation[4].

\subsection{Investment and Construction Subject.}

(1) Enterprise. At present, enterprises are subjects of investm ent and construction in China, including energy companies such as power grid companies and gas companies, as well as other social enterprises. However, in terms of technology, electricity and gas are the main types of energy supply, and the vast $m$ ajority of energy use is still driv en by electricity. Theref ore, grid companies will occupy a dominant position to provide continuous, safe and reliable power support, which is crucial for multi-energy interconnection operations.

(2) Users. Users are both users and beneficiaries of multi-energy interconnected operating systems. They can also invest on their own and obtain relevant economic benefits. Since $m$ ulti-energy interconnected operating systems are user-centric, th e relevant equipment is close to the location where users use it. At the sam e time, the investment in its subsystem equipment is not large, so the user can also become the investment subject.

\subsection{Investment and Construction Mode and Effect Analysis.}

In the future, electricity will becom e the li nk for various types of energy interconnection. Therefore, grid companies occupy an important position in multi-energy interconnected operations. In addition, according to the analysis in Section 2.1, useris also an important investor. Therefore, this section mainly analyzes the investment model of multi-energy interconnected operation systems from the perspectives of grid companies and users.

(1) PFI mode for investment and operation of power grid companies

Under this model, the government is mainly responsible for organizing, and the grid company as a leader in the planning, investm ent, financing, construction, and operation of $m$ ulti-energy interconnected operating system s. The com pany is both an investor and a system operator for scheduling and management.

(2) PFI mode for investment and operation of users

Under this model, large-user enterprises take the lead in investment, financing, construction and operations. After the com pletion of the main internal business services. The advantages of such projects mainly lie in the convenience of raising funds, electricity and heat energy can be consumed on the spot, but the scale is relatively limited. The advantages and disadvantages of the two modes are shown in Table 1.

Table 1. Advantages and inadequacies of the four investment construction models

\begin{tabular}{|c|c|c|}
\hline Model & Advantages & Disadvantages \\
\hline $\begin{array}{l}\text { PFI mode for investment } \\
\text { and operation of power grid } \\
\text { companies }\end{array}$ & $\begin{array}{c}\text { Beneficial to control projects' } \\
\text { construction and operating costs; } \\
\text { easy to clarify the responsibilities and } \\
\text { risks of each party; } \\
\text { helpful to take technical advantages } \\
\text { of the company. }\end{array}$ & $\begin{array}{l}\text { Hard to balance interests and } \\
\text { requirements of different stakeholders }\end{array}$ \\
\hline $\begin{array}{l}\text { PFI mode for investment } \\
\text { and operation of users }\end{array}$ & $\begin{array}{c}\text { Small investment, flexible } \\
\text { installation; } \\
\text { The market has a certain guarantee. }\end{array}$ & $\begin{array}{l}\text { Limited size; } \\
\text { low utilization rate. }\end{array}$ \\
\hline
\end{tabular}

Under the leading investm ent model of grid co mpanies, despite direct energy saving, it also reduces the power grid com pany's power supply load, which plays a positive role in the balance of 
power peaks and valleys and the protection of power grid security. This delays the expansion of power supply and substations and saves cost of power grid and generation construction.

The advantages of the user-led investment model are relatively obvious, the investm ent is small, the installation is flexible, and the $m$ arket has a certain guarantee. However, its scale is relatively limited, and the utilization rate is also limited by the size of users.

Therefore, based on the above analysis, it can be seen that in the early stage of the $m$ arket liberalization, the investment-building model of multi-energy interconnected networks dominated by the power grid is superior to other m odels. When the market is relatively complete, the user market can be opened up and appropriate investm ent space can be given to users. This can ensure the safe operation of multi-energy interconnection systems, increase the enthusiasm of users, and promote the rapid development of the system.

\section{Basic Service Model of Multi-Energy Interconnected Operation}

In the process of multi-energy interconnected operation, system operators need to provide users with diversified energy services, which $\mathrm{m}$ ainly include electrical energy services, heating services, information services, and demand-side management services [5, 6].

\subsection{Electricity Service.}

The energy of multi-energy interconnected operation mainly comes from clean distributed energy. Distributed generation is connected to users as well as the large power grid through micro-grid. The system can be constructed by the $m$ odel proposed in the previous section, equipped with energy storage facilities at the same time.

(1) Distributed Energy Development

Distributed energy sources is the $\mathrm{m}$ ain source of electricity in $\mathrm{m}$ ulti-energy interconnected operations. It include distributed photovolta ic, small wind turbines, distributed gas cooling-heating-power cogeneration system, fuel cell power stations and energy storage equipment. Different distributed energy developm ent strategies are different, and appropriate developm ent strategies should be adopted for each type of distributed energy.

(2) Micro grid Operation

The development of $\mathrm{m}$ icro-grid in $\mathrm{m}$ ulti-energy interconnection operations can realize high-reliability supply of $\mathrm{m}$ ultiple energy form $\mathrm{s}$ for loads. In the $\mathrm{m}$ ulti-energy interconnection operation, the grid structure should be strengthene d, new grid lines should be laid, and advanced smart grid technologies should be added. To ensure that users and system operators build distributed power generation connected to the main network, so as to achieve electricity self-balance with spare to grid-connected.

In terms of trading m echanism: distributed power is $m$ ostly intermittent renewable energy generation whose output is fluctuant and unpredictabe. For the characteristics of small power trading volume, large volatility of bidding output and inte rmittent strength, real-tim e trading m odel is recommended. While in term s of settlement mechanism: Considering various trading $\mathrm{m}$ echanisms comprehensively, it is recom mended that settlem ent methods be adopted after the settlem ent of unified price settlements. That is, the system operators of the micro grid will trade the rich energy in the distributed energy supply system with the main network at the unified settlement price [7].

\subsection{Heating Service.}

There are three channels for $m$ ulti-energy interconnected heating services. The first is the user-side heat pump technology [8]. It can be operated in the same way as a distributed power plant. The second is electric heating. By replacing the us er's heating equipment with electric heating by means of electricity substitution coal and electri city generation, the related expenses can be calculated uniformly through electricity charges. The third is to connect the heating channels in the system to the unified heating network and still obtain heating services from the public heating channels. At present, the first method is the most environmentally friendly and economically. 


\subsection{Information Service.}

With electricity market opened, information and data management will become one of the core competitiveness of the power industry. Corresponding monitoring equipment and cloud analysis and processing equipment will be constructed at en ergy supply and demand end, including information collection center, inform ation processing center a nd information feedback center, to analyze the characteristics of the user's energy use behavior. This lays the foundation for providing users with more energy-efficient solutions such as accura te energy supply, power dem and side management, and low-carbon energy conservation.

(1) Information Collection Center

The information collection center is equivalent tothe system's receiving module. Its main function is to com prehensively collect the user' $\mathrm{s}$ energy consumption data. According to a certain measurement and analysis model, the information collection center separately processes each data differently, and finally obtains the basic data required by the information processing center.

(2) Information Processing Center

The information processing center is the hub of the entire system, user energy data collected and consolidated by the inf ormation collection center can be transf ormed into the optim al energy use optimization solution through in-depth processing by the information processing center. Its $\mathrm{m}$ ain function is to display the user' $\mathrm{s}$ daily energy c onsumption and expenses, and provide users with energy consumption optimization services. The end user's power load curve can be sm oothed, and both sides of the energy supply and demand random interaction will be guided.

(3) Information Feedback Center

The information feedback center is the final $m$ odule of the inform ation system, and it is an information exchange section that im plements fixed feedback in conjunction with the optim ization plan formulated by the inform ation processing center. Its main function is to provide users with a daily energy bill at the end of each working day to indicate the user's daily energy costs and energy usage structure.

\subsection{Demand Side Management Service.}

In the com petitive market environment, both the power supply side and dem and side are characterized by random fluctuations. In order to adapt to this new situation, the demand side needs to implement the service $m$ odel of dem and side management. And the dem and side $m$ anagement services of multi-energy interconnected operations ar e closely linked with inform ation services. In multi-energy interconnected operation, demand-side management services can be implemented from the following four aspects.

Energy-saving services and energy performance contracting

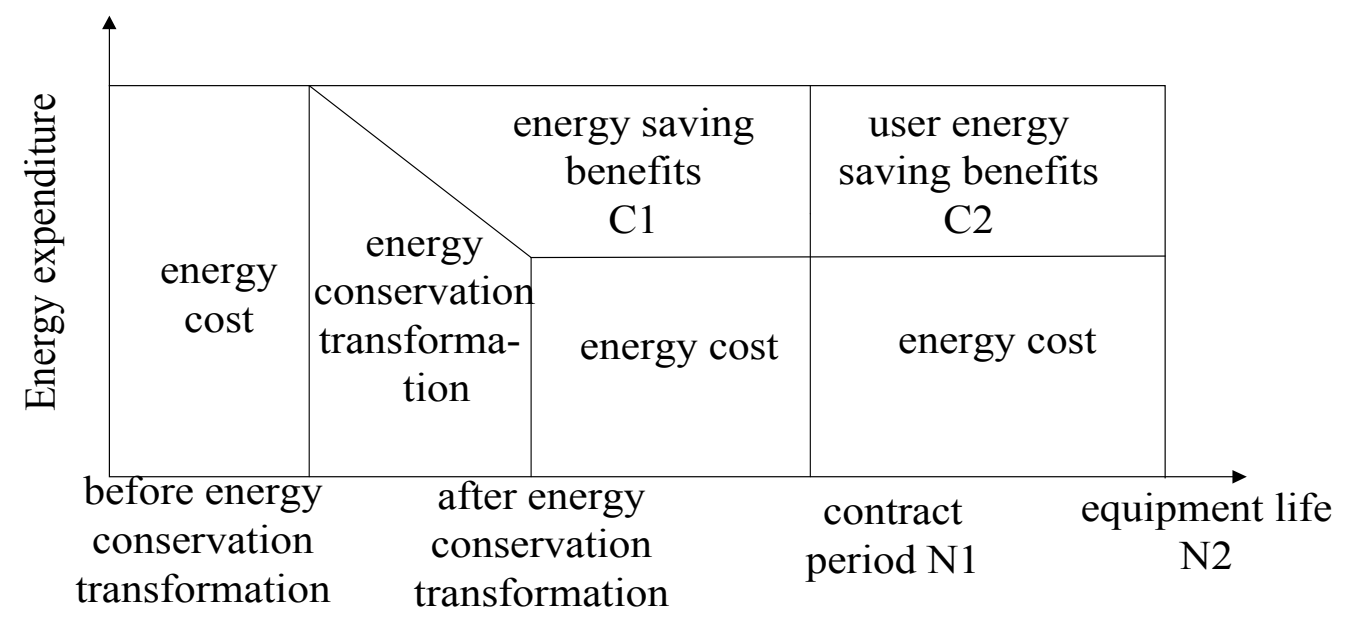

Figure 1. Distribution of benefits for contract energy management projects

(1) Energy performance contracting is a market-based energy-saving mechanism. It is based on the future energy-saving benefits as the current cost of energy-saving technology transform ation, upgrading, and replacement, so as to gradually redu ce the cost of energy costs to save energy and improve energy efficiency. The income distribution method is shown in Figure 1. 
(2) Optimize power plan service

The company should $\mathrm{m}$ ake full use of the de mand side $\mathrm{m}$ anagement resources under the multi-energy interconnection operation. Specifically, by installing a smart meter on the user side, the daily load curve, the type of electricity used per hour, and the electricity price of each type of electrical appliances among residential users can be obtained. Moreover, establishing a reasonable power-supply optimization scheme based on price -responsive to $\mathrm{m}$ inimize the user' $\mathrm{s}$ power consumption cost, effectively improve the quality of service.

(3) Electrical diagnostic service

The electricity diagnosis service is aimed at the phenomenon of large power consumption but low efficiency or unreasonable distribution of peak power and valley power, etc., and then provides comprehensive analysis of power consum ption and puts forward corresponding professional suggestions for users.

(4) App Self Service

Combining the construction of inform ation systems in multi-energy interconnection operations, system operators can develop mobile phone software on electricity usage. This enables users to track and analyze electricity at any time and provides support for several other demand-side management services.

\section{Multi-Energy Interconnection Operating Profit Model}

Multi-energy interconnection operators not only need to be responsible for system operations, but also participate in the construction and investment of some infrastructure within the system. Its main profit-making channels include electricity revenue, heating revenue, information service revenue and negative watt return.

\subsection{Electricity Revenue.}

The system operation business develops distri buted power stations within the $\mathrm{m}$ ulti-energy interconnection operation system, provides users with power supply and charges for electricity. In addition, system operators also need to build a micro grid between distributed energy and large grids, between distributed energy sources and users. This part of the cost should be included in the electricity cost of per $\mathrm{KW} \mathrm{h}$, in a similar way to the transmission and distribution electricity price. Moreover, distributed generation follows the $\mathrm{m}$ odel of self-use, surplus online. $\mathrm{W}$ hen distributed generation generates excess electricity, system operators can purchase this portion of electricity from users and sell it to the grid to earn some of the price difference.

Therefore, electricity revenue can be calculated as follows:

$$
R_{e}=R_{D G}+R_{m}+R_{p}
$$

Where the $R_{e}$ is electricity revenue, $R_{D G}$ is distributed generation tariff, $R_{m}$ is micro-grid cost and $R_{p}$ is distributed margin electricity price difference.

$$
R_{D G}=I \times A / C_{e}+P
$$

$I$ Is distributed generation investm ent, $A$ is equivalent paid-up capital recovery factor, $C_{e}$ is annual electricity consumption and $P$ is reasonable return.

$$
R_{m}=\left[\left(C_{u}+C_{i}\right) \times A+C_{o}\right] / C_{e}+P
$$

$C_{u}$ Is grid upgrade cost, $C_{i}$ is new grid investment cost and $C_{o}$ is system operating cost.

\subsection{Heating Revenue.}

System operators should build distributed heat pump heating on a user-by-user basis or actively explore other distributed heating m odes. The user's charging method is the sam e as the electricity charge. The formula is:

$$
R_{h}=\sum\left(I_{p} \times A / d+P\right)
$$

Where $R_{h}$ is heating service fee, $I_{p}$ is heat pump investment of per user, A is equivalent paid-up capital recovery factor, $\mathrm{d}$ is annual heating days and $\mathrm{P}$ is reasonable return. 
If the multi-energy interconnection operation in th e area uses electric heating, the electricity revenue will cover the heating benefits; if the areastill receives heat from the public heating network, this part of heating revenue belongs to the heating company.

\subsection{Information Service Revenue.}

This part of the fee follows the user-defined principle and charges according to the user' $\mathrm{s}$ customized energy information service. This part of the information costs should be less than the user's savings in electricity expenses, otherwise the user will not be able to obtain the benefits of this service, and will lose motivation to use the service.

\subsection{Negative Watt Revenue.}

The negative watt revenue is closely linked to therevenue of information services. Because system operators have a large number of monitoring devices at the user end and energy supply end, they can meticulously characterize and analyze users' energy use behavior and provide optimized energy use solutions. Therefore, the user can also reduce the load or transfer part of the load at a specific tim e. This part of the load we call "negative watts." For grid companies, this part of the negative tile can shift the peak load to the base load, so the systemoperator can sell this part of the negative watt to the grid companies for profit.

In summary, the revenue of the multi-energy interconnections operation system can be calculated as follows:

$$
R_{S}=R_{e}+R_{h}+R_{i}+R_{w}
$$

Where the $R_{S}$ is revenue of the multi-energy interconnections operation system, $R_{e}$ is electricity revenue, $R_{h}$ is heating income, $R_{i}$ is information service revenue and $R_{w}$ is negative tile gain.

\section{Conclusion}

During the 13th five-year plan period, great changes have taken place in the characteristics of the energy market and the environm ent of $\mathrm{m}$ arket operation. Realizing $\mathrm{m}$ ulti-energy interconnected operation is important to the development of energy companies. In current situation, the investment and construction model of multi-energy interconnected systems led by power grid enterprise has a higher superiority and better developm ent prospects. When energy $m$ arket become mature, it is possible to open user $\mathrm{m}$ arket to achieve a win- win result among the government, enterprises, and users. In addition, the current study of the service model and profit $m$ odel of $m$ ulti-energy interconnection operation in this paper is confined only to the econom ic benefits, while the system emphasizes more on low-carbon benefits and ci rcular economy. Some economic benefits will actually transform into social benefits, so the sœial benefits of multi-energy interconnected operation system will be considered and quantized in the $f$ uture research and practice, thus com prehensively measure its value and contribution.

\section{Acknowledgments}

The paper is supported by Science and Technology Project of SGCC (SGTJDK00DWJS1700027) and Research Base Program Supported by Beijing Social Science Research Funding (15JDJGA089).

\section{References}

[1]. Wang Jinan, Gao Hogue, Yan Yongcai, et al. Business Model Innovation of Energy Internet and Chinese Utilities[J],Science and Technology Management Research.2017, 37(8):26-32.

[2]. Li Bo. Discussion on the world outlook and $\mathrm{m}$ ethodology of transformation and upgrading of power grid enterprises - - To build a comprehensive energy solutions and service platform for enterprise[J].Guiyang Power Supply Bureau. 2017, 20(2):29-42.

[3]. Wang Hokusai, LIU Da. Study on Power Supply Service Business Model Innovation in Power Grid Company under Energy Internet[J].Shanxi Electric Power,2016, 44(8):47-50. 
[4]. Deng Xin. The Investm ent and Construction M odes of Integrated Energy System $\mathrm{s}$ in Low Carbon Economy. Techno economics \& Management Research.2013 (7):11-15.

[5]. Zeng Ming, Liu Hangzhou, Xu Song. Commercial Investment Model and Implementation Path of Distributed Energy Resources. East China Electric Power. 2012(3):344-348.

[6]. Zhang Aiming. Study on the $m$ anagement mode of power grid enterprises in sm art grid environment. Low Carbon World, 2017(20):98-99.

[7]. Xin Lichen, Dong Zhao yang, Xu Yan, etc. Busine ss Mode Analysis of Energy Internet Based Micro grids. Southern Power System Technology. 2016, 10(8):17-22.

[8]. Hue Yi, Liu Ying. Discussion cogeneration district heating operation mode and operating costs. District Heating, 2014(1):104-108. 